\title{
INISIASI TEKNOLOGI HAYATI PADA PETANI UNTUK MENDUKUNG REVEGETASI LAHAN BEKAS PERLADANGAN
}

\section{INITIATION OF BIOLOGICAL TECHNOLOGYTO FARMERS FOR SUPPORTING REVEGETATION OF EX-SHIFTING CULTIVATION LAND}

\author{
${ }^{1)}$ Hanna Artuti Ekamawanti, ${ }^{2}$ Herkulana \\ ${ }^{1,2)}$ Fakultas Kehutanan Universitas Tanjungpura \\ J1. Daya Nasional Pontianak 78124, Kalimantan Barat \\ email: hannaartuti@fahutan.untan.ac.id
}

\begin{abstract}
ABSTRAK
Masyarakat di desa Antan Rayan Kabupaten Landak, Kalimantan Barat, belum produktif secara ekonomis, tetapi berhasrat kuat untuk berwirausaha dengan memanfaatkan potensi sumberdaya lokal. Kegiatan ini bertujuan menginisiasi munculnya wirausahawan pertanian dengan pengetahuan dan keterampilan menghasilkan produk arang sekam dan produk teknologi hayati mikoriza untuk pembuatan bibit unggul. Khalayak sasaran yang dijadikan sebagai mitra adalah kelompok tani Naremang dan kelompok pemuda GPdI, khususnya di Nangun Nuyung. Metode yang digunakan adalah pendidikan masyarakat dan difusi ilmu pengetahuan dan teknologi. Tahapan kegiatan yang dilakukan tahap penyadaran (penyuluhan dan pembekalan/bimbingan teknis) dan tahap penumbuhan (pendampingan praktis, pengawasan dan evaluasi). Hasil menunjukkan $70 \%$ peserta dapat memahami materi tentang potensi dan peluang pengembangan wirausaha pertanian. Persentase anggota mitra yang dapat membuat arang sekam 50\%, 30\% dapat membuat inokulum mikoriza dan bibit unggul dari 10 orang yang aktif mengikuti kegiatan ini.Produk teknologi hayati yang dihasilkandalam bentuk inokulum mikoriza arbuskula dan produk arang sekam tersebut dapat digunakan untuk membuat bibitbibit unggul tanaman penghasil kayu dan buah-buahan. Selain dapat menunjang keberhasilan revegetasi lahan bekas perladangan, produk-produk tersebut juga dapat dijadikan peluang usaha mitra yang bernilai ekonomis yang dikelola oleh koperasi unit desa melalui pembentukan pengurus.
\end{abstract}

Kata kunci: Inokulum Mikoriza; Arang Sekam; Bibit Unggul

\section{ABSTRACT}

The people in the village of Antan Rayan, Landak Regency, West Kalimantan, have not been economically productive, but have a strong desire to do business by utilizing the potential of local resources. This activity aims to initiate the emergence of agricultural entrepreneurs with the knowledge and skills to produce husk charcoal products and mycorrhizal biological technology products for the production of superior seeds. The target audience used as partners is the Naremang farmer group and the GPdI youth group, especially in Nangun Nuyung. The method used is public education and the diffusion of science and technology. Stages of activities carried out at the awareness stage (counseling and briefing / technical guidance) and the growth stage (practical assistance, supervision, and evaluation). The results showed that $70 \%$ of participants could understand material about the potential and opportunities for developing agricultural entrepreneurs. The percentage of partner members who can make 50\% husk charcoal, 30\% can make mycorrhizal inoculums and superior seeds from 10 people who actively participate in this activity. Superior timber and fruit-producing plants in addition to supporting the success of revegetation of ex-cultivation land, these products can also be used as business opportunities of economic value partners managed by village unit cooperatives through the formation of management

Keywords: Mycorrhizal Inoculum; Husk Charcoal; Superior Seedlings 


\section{PENDAHULUAN}

Sebagaimana umumnya kondisi di lahanbekasperladangan yang memiliki kesuburantanah yang rendah, input energi berupa pemupukan menggunakan pupuk kimia sangat diperlukan. Namun, kelemahan menggunakan pupuk kimia adalah residu yang ditinggalkannya dapat menimbulkan pencemaran lingkungan. Upaya untuk merevegetasi lahan bekas perladangan dapat didukung dengan menggunakan bibit unggul yang dihasilkan dari pembibitan yang mengaplikasikan teknologi hayati, seperti inokulasi bibit dengan inokulum mikoriza (inokulum FMA) dan penggunaan media tanam untuk pembibitan yang dicampur dengan arang sekam. Hal ini telah menginspirasi untuk diterapkannya teknologi mikoriza dan arang sekam selama pembuatan bibit tanaman. Penggunaan mikoriza sebagai biofertilizer (pupuk hayati) untuk kelestarian budidaya pertanian direkomendasikan oleh Solaiman, et all, (2014) ; Weber (2014).

Program Kemitraan Masyarakat (PKM) yang merupakan salah satu kegiatan pengabdian kepada masyarakat dengan menerapkan paradigma baru yang bersifat penyelesaian masalah (problem solving), komprehensif, bermakna, tuntas dan harus mempertimbangkan keberlanjutan (sustainable) (Direktorat Riset dan Pengabdian Kepada Masyarakat 2017) pada dua kelompok mitra sebagai khalayak sasaran. Khalayak sasaran yang dijadikan sebagai mitra adalah kelompok tani Naremang dan kelompok pemuda GPdINangun Nuyung dusun Sungai Durian desa Antan Rayan memiliki karakteristik masyarakat yang belum produktif secara ekonomis, namun sangat berkeinginan kuat untuk berwirausaha, khususnya di bidang pertanian. Kondisi masyarakatnya masih berada pada jenjang puas hanya dengan pemenuhan kebutuhan primer sehari-hari dari hasil pertanian sawah (padi), sehingga tidak terpacu untuk mencari peluang usaha yang dapat dimanfaatkan untuk lebih meningkatkan taraf hidup, tidak memiliki kemampuan mengorganisasi usaha, dan tidak memiliki kemampuan bersaing. Namun, sebagian besar masyarakatnya masih mempertahankan lahan mereka tidak dikonversi menjadi areal tanam kelapa sawit,walaupun sebagian masyarakat desa sekitarnya tidak lagi berladang karena lahan sudah disewakan kepada perusahaan perkebunan kelapa sawit.

Lahan bekas ladang berpindah yang ada di dusun Sungai Durian merupakan salah satu potensi sumber daya alam yang dapat dikembangkan menjadi lahan produktif untuk meningkatkan pendapatan masyarakat. Alternatif kegiatan yang dapat dilakukan adalah revegetasi lahan dengan penanaman berbagai jenis tanaman untuk tujuan produksi. Hal ini merupakan salah satu potensi usaha yang dapat dikembangkan oleh mitra. Pengadaan bibit-bibit tanaman untuk menunjang keberhasilan revegetasi lahan bekas perladangan berpindah dapat dijadikan peluang usaha mitra melalui pembuatan pembibitan unggul dengan aplikasi inokulum mikoriza arbuskula sebagai agens hayati. Dasar pemikirannya adalah melalui pembuatan pembibitan unggul, mitra tidak hanya dapat menggunakan bibit-bibit yang akan dibuat untuk revegetasi lahan tetapi juga dapat menjualnya kepada masyarakat tani di luar wilayahnya. Peluang usaha ini sangat memungkinkan akan menghasilkan wirausahawan tani dari desa Antan Rayan. Pembuatan pembibitan unggul oleh mitra juga dapat mengurangi tingkat ketergantungan masyarakat terhadap penangkar bibit dari luar desanya dan bantuan bibit dari pemerintah. Selain itu, produksi inokulum mikoriza arbuskula sebagai agens hayati untuk menunjang pembibitan unggul dan mengurangi penggunaan pupuk kimia juga merupakan 
peluang usaha. Potensi lain yang ada di Nangun Nuyung, yaitu limbah sekam padi yang banyak terdapat di lokasi mitra dapat dijadikan arang sekam yang bermanfaat untuk media tumbuh dalam pembibitan dan dapat dikemas untuk dijual ke pengguna lainnya.

Hasil survei awal diketahui bahwa masyarakat menghendaki lahan bekas perladangan berpindah dapat ditanami dengan jenis-jenis pohon buah-buahan dan kayu untuk tujuan produksi. Namun ada kendala teknis yang dihadapi kelompok mitra untuk mewujudkan keinginan mereka berwirausaha dengan memanfaatkan sumber daya setempat yang ada di desa mitra. Permasalahan prioritas yang dihadapi mitra dari segi produksi yaitu : 1) Belum semua anggota masyarakat desa Antan Rayan, khususnya yang tergabung dalam kelompok tani Naremang di Nangun Nuyung dusun Sei Durian, memiliki visi untuk meningkatkan taraf hidupnya dengan berwirausaha pertanian, 2) Keterbatasan ketersediaan bibit-bibit unggul yang akan ditanam apabila lahan tidur mereka akan ditanami dengan pohon-pohon untuk tujuan produksi, bahkan untuk beberapa jenis pohon buah-buahan maupun pohon untuk produksi kayu tidak tersedia di desa mereka. Benih-benih dan/atau bibit-bibit tanaman yang akan ditanam tidak semuanya tersedia di lokasi mitra sehingga harus didatangkan dari daerah lain. Kelemahannya adalah kualitas benih dan/atau bibit yang diperoleh terkadang kurang/tidak baik. 3) Tingkat kesuburan tanah yang rendah di lahan bekas perladangan dan mereka belum pernah mendapatkan informasi terkait penggunaan atau aplikasi pupuk hayati mikoriza arbuskula yang dapat mengurangi penggunaan pupuk kimia. Apabila lahanlahan tersebut akan diolah kembali tentunya membutuhkan input energi yang cukup besar, mulai dari tahap persiapan lahan, penanaman dan pemeliharaannya hingga panen. Tantangan lain yang dihadapi adalah sebagian masyarakat desa Antan Rayan sudah menginvestasikan lahannya kepada pengusaha perkebunan sawit sehingga tidak menutup kemungkinan lahan masyarakat Nangun Nuyung yang saat ini masih belum diusahakan juga akan dikonversi menjadi lahan kelapa sawit.4) Masyarakat Nangun Nuyung belum tahu cara memanfaatkan limbah padi berupa sekam padi agar memiliki nilai jual dengan membuatnya menjadi arang sekam.

Kegiatan PKM pada kedua kelompok mitra ini dimaksudkan untuk menginisiasi munculnya wirausahawan pertanian melalui tahapan kegiatan yaitu tahap penyadaran (penyuluhan dan pembekalan/bimbingan teknis) dan tahap penumbuhan (pendampingan praktis, pengawasan dan evaluasi). Tujuan kegiatan ini adalah meningkatkan produk bibit-bibit unggul tanaman penghasil kayu dan buahbuahan, produk inokulum mikoriza (khususnya inokulum fungi mikoriza arbuskula/FMA) dan produk arang sekam yang dapat dibuat sendiri oleh kelompok tani Naremang bersama dengan kelompok pemuda GPdI. Dalam jangka panjang, produk-produk tersebut tidak hanya untuk digunakan oleh masyarakat sasaran tetapi juga untuk dijual ke pasar lokal.

\section{METODE}

Metode yang diterapkan disesuaikan dengan karakteristik masyarakat sasaran yang memiliki tingkat pendidikan, keterampilan dan kesadaran untuk mengembangkan potensi sumber daya lokal yang masih rendah. Pola pikir yang masih sederhana dan tidak memiliki visi yang jelas untuk menjadi masyarakat mandiri dan produktif. Pengetahuan masyarakat masih sangat terbatas untuk mengolah limbah hasil pertanian, seperti sekam padi menjadi arang sekam yang memiliki nilai ekonomis. Kegiatan ini dilaksanakan ini berbasis pada karakteristik masyarakat Nangun Nuyung dusun Sungai Durian desa Antan Rayan, kabupaten Landak Kalimantan Barat, memiliki sebagai sumber daya manusia yang memiliki hasrat untuk memulai usaha baru 
(wirausaha). Kelompok tani Naremang tidak memiliki program khusus dalam berusaha tani untuk mengembangkan komoditas pertanian lainnya dan sebatas hanya melaksanakan program menanam padi milik kelompok tani hasil bantuan dari pemerintah yang ditanam di sawah anggota kelompok tani secara bergilir dan sukarela. Kelompok pemuda GPdI termasuk kelompok produktif dengan menjadi buruh perkebunan sawit di wilayah sekitar desanya, namun mereka belum mandiri untuk mengelola usaha di desa.

Metode yang digunakan adalah pendidikan masyarakat dan difusi ilmu pengetahuan dan teknologi melalui tahapan penyadaran dan penumbuhan, sebagai solusi masalah yang dihadapi kelompok mitra. Metode pendekatan yang dilakukan pada masing-masing tahapan, antara lain:

1. Tahap penyadaran, berupa ceramah dan diskusi untuk membuka wawasan mitra dengan memberikan informasi dan motivasi untuk mengubah pola pikir/paradigma lama yang hanya sekedar bertahan hidup menjadi hidup yang lebih produktif. Selain itu juga petani diberi pembekalan teori tentang peranan dan manfaat agens hayati (khususnya mikoriza arbuskula) dan manfaat dan nilai jual arang sekam. Pada tahap ini, kegiatan dilakukan di dalam ruangan dan dilaksanakan pada awal dari keseluruhan kegiatan. Tanya jawab dan diskusi dilakukan untuk lebih efektifnya kegiatan yang dilakukan. Pada akhir kegiatan, audiens diberi kuisioner untuk mengetahui tingkat pemahaman masyarakat terhadap materi yang disampaikan.

2. Tahap penumbuhan, berupa bimbingan (pendampingan) teknis:

a. Praktik produksi inokulum mikoriza arbuskula. Perbanyakan inokulum mikoriza menggunakanstarter inokulum mikoriza komersil dengan semai jagung sebagai tanaman inang dalam pot-pot kultur di rumah kasa. Pra inokulasi dilakukan di bak perkecambahan pada media zeolit selama dua minggu, kemudian semai jagung dipundah ke dalam pot-pot kultur yang sudah diisi zeolit sebagai media tumbuh sekaligus carrier inokulum dan 0,5-1 g inokulum mikoriza. Inkubasi kultur mikorizadilakukan di rumah kasa yang cukup sinar matahari dan pemeliharaan dengan penyiraman dan pemupukan, selama 3 bulan. Pada akhir bulan ketiga dilakukan stressing dengan dengan cara tidak disiram dan dipupuk selama dua minggu. Kultur mikoriza sebelum dipanen, dilakukan topping, yaitu tajuk tanaman inang dipotong dan disisakan bagian bawahnya kurang lebih tinggal 3/4-nya saja. Selanjutnya akar tanam ninang dipotong kecil-kecil dan dicampur dengan zeolit dan dikemas dalam kantong plastik yang diberi label.

b. Praktik pembuatan arang sekam dengan menggunakan cerobong kawat kasa baja yang digulung dengan diameter lebih kurang $10 \mathrm{~cm}$ dan diikat dengan tali kawat baja. Api unggun dibuat menggunakan bahan bakar dari kayubakar, ranting, kertas koranataudaun-daunkering. Saat telah terbentuk bara api, sekam padi ditempatkan mengelilingi cerobong pembakaran hingga setinggi kurang lebih setengah dari tinggi cerobong. Setelah 20-30 menit atau saat puncak timbunan sekam padi terlihat menghitam, sekam yang masih berwarna coklat dinaikkan kearah puncak dan dilakukan terus sampai semua sekam padi menghitam sempurna. Setelah semua sekam berubah menjadi hitam, sekam disiram dengan air hingga merata untuk menghentikan proses pembakaran. Setelah disiram dan suhunya menurun, gunungan arang sekam dibongkar dan dikeringanginkan dan setelah dingin dimasukkan kedalam karung dan disimpan di tempa kering. Pengemasan dilakukan dalam kantong 
plastik transparan kemudian kantong kemasan ditutup dengan sealer kantong plastik kemudian diberi label.

c. Praktik pembuatan pembibitan unggul dari benih dan setek

Pembuatan bibit unggul dari benih dilakukan dengan melakukan pra inokulasi mikoriza saat pengecambahan benih tanaman dengan teknik berlapis (layering technique) di bak perkecambahan, yang telah diisi dengan media zeolit atau pasir sungai yang telah dicuci bersih. Selanjutnya benih-benih dalam bak kecambah tersebut ditempatkan di rumah kasa sampai terbentuk daun (tanaman yang sempurna), semai siap disapih di dalam polybag yang telah diisi dengan media tanam (campuran tanah:serbuk gergaji:arang sekam 3:1:1). Tahap inokulasi mikoriza dilakukan saat bibit tanaman dari bak kecambah disapih ke dalam polybag tersebut. Pemeliharaan bibit dilakukan selama 3 bulan dengan pemupukan rendah $\mathrm{P}$ dan penyiraman.

Pembuatan bibit unggul dari setek dapat dilakukan apabila umur setek yang akan dibuat bibit kurang dari 1 bulan karena bila lebih dari 1 bulan, akar tanaman sudah terlignifikasi sehingga inokulasi mikoriza tidak akan efektif. Tahapan inokulasi di polybag yang telah diisi dengan media sapih sama dengan tahapan inokulasi bibit yang berasal dari benih.

\section{HASIL DAN PEMBAHASAN}

Kegiatan PKM yang dimulai dengan tahap penyadaran telah menumbuhkan keingintahuan yang besar dan kemauan yang kuat dari masyarakat untuk mengenal dan mengaplikasikan teknologi hayati mikoriza dan pemanfaatan sekam padi yang selama ini belum dimanfaatkan. Hal ini nampak saat diskusi dengan peserta selama kegiatan berlangsung dan dipastikan oleh ketua kelompok tani Naremang untuk kegiatan pelatihan pembuatan arang sekam, perbanyakan inokulum mikoriza dan aplikasi keduanya pada pembuatan bibit unggul dapat diberikan pada tahap pelatihan. Berdasarkan hasil kuesionersebelum dan setelah pelaksanaan PKM pada tahap penyadaran diketahui $70 \%$ dari total peserta sebanyak 20 orang dapat memahami materi PKM tentang potensi dan peluang pengembangan wirausaha pertanian.

Pada tahap penumbuhan, pelatihan dilakukan dalam dua tahap, yaitu tahap pembuatan arang sekam dan perbanyakan inokulum mikoriza, serta tahap pemanenan inokulum mikoriza dan pembuatan bibit unggul. Pada pelatihan ini, persentase anggota mitra yang dapat membuat arang sekam 50\%, 30\% dapat membuat inokulum mikoriza dan bibit unggul dari 10 orang yang aktif selama pelatihan. Hasil kegiatan pelatihan yang telah dilaksanakan sebagai solusi permasalahan yang diberikan kepada kelomppok masyarakat sasaran sebagaimana tercantum pada Tabel 1 .

Tabel. Solusi yang diberikan kepada mitra dan luaran yang diperoleh mitra

\begin{tabular}{|c|c|}
\hline Solusi yang Diberikan & Jenis Luaran \\
\hline $\begin{array}{l}\text { Pelatihan pembuatan } \\
\text { arang sekam dengan } \\
\text { memanfaatkan limbah } \\
\text { sekam padi yang banyak } \\
\text { terdapat di lokasi mitra. }\end{array}$ & $\begin{array}{l}\text { Produk arang sekam padi } \\
\text { dalam kemasan per } \\
\text { satuan berat. }\end{array}$ \\
\hline $\begin{array}{l}\text { Pelatihan pembuatan } \\
\text { inokulum mikoriza } \\
\text { arbuskula pada skala } \\
\text { rumah kasa. }\end{array}$ & $\begin{array}{l}\text { - Rumah kasa untuk } \\
\text { produksi inokulum } \\
\text { mikoriza arbuskula. } \\
\text { - Produk inokulum } \\
\text { mikoriza arbuskula } \\
\text { dalam bentuk granul. }\end{array}$ \\
\hline $\begin{array}{l}\text { Pelatihan pembuatan } \\
\text { pembibitan unggul jenis } \\
\text { pohon buah-buahan dan } \\
\text { pohon penghasil kayu. }\end{array}$ & $\begin{array}{l}\text { - Persemaian sederhana } \\
\text { berupa bedeng } \\
\text { perkecambahan dan } \\
\text { bedeng penyapihan. } \\
\text { - Produk bibit-bibit } \\
\text { unggul jenis pohon } \\
\text { buah-buahan dan } \\
\text { pohon penghasil kayu. }\end{array}$ \\
\hline
\end{tabular}

Mikoriza yang dikemas dalam bentuk inokulum berbentuk granul (Gambar 1), atau lebih dikenal sebagai pupuk hayati, sesungguhnya merupakan agens hayati 
yang memiliki peran ekologis penting karena dapat membantu tanaman menyerap hara, terutama yang dominan adalah fosfat (Smith \& Read 2008; Marschner 2012). Ekamawanti, et all, (2013) telah membuktikan bahwa mikoriza arbuskula dapat meningkatkan akumulasi unsurunsur hara makro $(\mathrm{N}, \mathrm{P}, \mathrm{K}, \mathrm{Ca}$ dan $\mathrm{Mg}$ ) pada semai tanaman sengon buto (Enterolobium cyclocarpus) sehingga semai dapat tumbuh sehat dan besar. Aplikasi mikoriza juga dapat meningkatkan produksi jagung (Fitri dan Nurul 2014). Oleh karena itu, inokulum mikoriza juga dapat dimanfaatkan sebagai alternatif untuk mengurangi penggunaan pupuk kimia. Manfaat lain dari mikoriza adalah dapat meningkatkan daya tahan tanaman terhadap logam berat beracun, seperti merkuri (Ekamawanti, et all, 2014), di mana merkuri diketahui merupakan salah satu residu pada pestisida, dapat meningkatkan tanaman terhadap serangan patogen tanah (Comby, et all, 2017). Pada kegiatan ini, petani dikenalkan dengan teknologi mikoriza serta diberi pelatihan bagaimana membuat produk inokulum mikoriza dan cara mengaplikasikannya pada bibit tanaman dengan benar. Kelompok tani juga telah membangun rumah kasa sebagai tempat untuk produksi massal inokulum mikoriza dan untuk menjamin kualitas dari produk inokulum mikoriza yang dihasilkan, kelompok tani dibantu oleh nara sumber di Fakultas Kehutanan Universitas Tanjungpura. Transfer teknologi hayati mikoriza ini juga pernah dilakukan oleh Hajoeningtijas dan Suyadi (2011). Hal ini menunjukkan bahwa teknologi hayati mikoriza merupakan teknologi yang dapat langsung digunakan oleh masyarakat petani.

Kelanjutan dari kegiatan ini terus diupayakan dengan melibatkan kelompok UKM mahasiswa Fakultas Kehutanan (Forestry) dengan melakukan pendampingan dan membantu dalam pemasaran produk yang dihasilkan oleh kelompok tani Naremang. Produk arang sekam padi bahkan sudah dijual dalam bentuk kemasan untuk meningkatkan nilai ekonomi yang tadinya dianggapl imbah. Saat ini produk arang sekam Naremang dipasarkan melalui media online seperti Instagram (@naremang_berkara) dan Facebook Naremang (naremangsquad@gmail.com).

Penggunaan bibit unggul dengan memanfaatkan inokulum mikoriza sebagai agens hayati dan penggunaan arang sekam akan dapat menunjang pertumbuhan bibit saat ditanam di lahan-lahan yang miskin hara sebagaimana yang terdapat di lahan bekas perladangan di Nangun Nuyung. Manfaat ekologis yang diperoleh, tidak hanya bagi tanaman tetapi juga bagi lingkungan. Apabila tanaman sudah dikolonisasi oleh fungi mikoriza arbuskula yang bersumber dari inokulum yang diberikan maka seumur hidup tanaman akan merasakan manfaatnya sehingga penggunaan pupuk kimia juga dapat dikurangi (Comby, et all, 2017). Pencemaran lingkungan akibat penggunaan pupuk kimia dan fungisida juga dapat dikurangi. Bibit unggul bermikoriza dapat memberikan keungunan ganda berupa keuntungan ekologis dan ekonomis. Penggunaan arang sekam pada pembibitan juga akan menunjang kesehatan tanaman mengingat arang sekam juga dapat mencegah serangan patogen tanah yang dapat merugikan tanaman. Produk bibit unggul yang dihasilkan tidak hanya dapat digunakan langsung oleh kelompok tani, tetapi juga dapat dijual. Bibit unggul yang dihasilkan dapat bersaing dengan bibitbibit tanaman yang diproduksi oleh kelompok lain, mengingat keunggulan yang dimilikinya.

Indikator keberhasilan kegiatan ini adalah petani dapat membuat sendiri arang sekam, inokulum mikoriza dan bibit unggul. Total peserta pelatihan sebanyak 20 orang yang, namun hanya 10 orang yang benar-benar aktif mengikuti setiap tahap pelatihan. Pada akhir kegiatan, sebanyak $5(50 \%)$ orang sudah dapat membuat arang sekam, 3 (30\%) orang yang membuat inokulum mikoriza dan 
bibit unggul.Target jangka panjang yaitubibit-bibitunggultanaman yang diperolehselain dimanfaakan kelompok tani untuk ditanam di lahan anggota, juga selebihnya dapat dijual kepasar lokal. Selain itu, anggota kelompok mitra juga dapat memanfaatkan inokulum mikoriza arbuskula dan arang sekam dalam pembibitan dan selebihnya dijual ke pasar. Penjualan bibit unggul, inokulum mikoriza arbuskula dan arang sekam dilakukan untuk memberikan contoh kepada masyarakat agar dapat meningkatkan pendapatan anggota kelompok dari usaha pembibitan mandiri dan pengolahan limbah padi, serta mendorong masyarakat untuk menanam bibit unggul sehingga mendapatkan kualitas produksi yang lebih baik.

\section{KESIMPULAN}

Kegiatan PKM yang telah dilaksanakan dan diikuti dengan antusis oleh kedua mitra, yaitu kelompok tani Naremang dan kelompok pemuda GPdI di desa Antan Rayan telah dilakukan secara bertahap. Hasil yang diperoleh mitra adalah mitra dapat membuat produk berupa arang sekam, inokulum mikoriza arbuskula dan bibit unggul.

Kegiatan seperti PKM dengan melibatkan partisipati masyarakat dengan memanfaatkan teknologi hayati mikoriza dan pemanfaatan limbah sekam padi sangat direkomendasikan untuk ditindaklanjuti dalam kegiatan berikutnya berupa pelatihan cara persiapan lahan tanam, praktik penanaman bibit unggul dan pemeliharaannya. Hal ini dimaksudkan untuk keberlanjutan hasil kegiatan PKM yang sudah diperoleh masyarakat sasaran

\section{UCAPAN TERIMA KASIH}

Terimah kasih kepada Direktorat Riset dan Pengabdian Masyarakat, Direktorat Jenderal Penguatan Riset dan Pengembangan, Kementerian Riset, Teknologi dan Pendidikan Tinggi yang telah mendanai kegiatan ini melalui skema
Program Kemitraan Masrayakat (PKM) tahun anggaran 2018.

\section{DAFTAR PUSTAKA}

Comby, M., Mustafa G., Magnin-Robert M., Randoux B., Fontaine J., Reignault PH., Lounès-Hadj Sahraoui A., (2017). Arbuscular Mycorrhizal Fungi as Potential Bioprotectants Against Aerial Phytopathogens and Pests. Di dalam Wu Q-S (editor). Arbuscular Mycorrhizas and Stress Toleranceof Plants. Singapore: Springer Nature.

Ekamawanti, HA., Setiadi, Y., Sopandie, D., Santosa, DA., (2014). Mercury Stress Resistances In Naucleaorientalisseedlings Inoculated With Arbuscular Mycorrhizal Fungi. Agriculture, Forestry and Fisheries 3(2):113-120.

Ekamawanti, HA., Setiadi, Y., Sopandie, D., Santosa, DA., (2013). The Role Of Arbuscular Mycorrhizal Fungus (Gigaspora Margarita) On Mercury And Nutrients Accumulation By Enterolobiumcyclocarpum Seedlings. Microbiology Indonesia, 7 (4) : 167176

Fitri, A, \& Nurul S. (2014). Peningkatan produksi jagung melalui penggunaan mikoriza dan pupuk hayati di Desa Bakung Kecamatan Indralaya Utara Kabupaten Ogan Ilir Sumatera Selatan. Jurnal Pengabdian Sriwijaya 2(2): 117-123.

Hajoeningtijas, O D., \& Suyadi A., (2011). Transfer Teknologi Perbanyakan Pupuk Hayatimikoriza Pada Petani Sebagai Upaya Mendukung Pertanian Berkelanjutan. Agritech. 13 (2): 125-139.

Marschner P. (2012). Mineral Nutrition of Higher Plants. Third Edition. USA: Elsevier. 
Smith, SE., \& Read, DJ., (2008). Mycorrhizal Symbiosis, $3^{\text {rd }}$ edition, Elsevier, New York.

Solaiman, ZM., \& Mickan B. (2014). Use of Mycorrhiza in Sustainable Agriculture and Land Restoration. Di dalam Solaiman ZM, Abbott LK, Varma A. (editor). Mycorrhizal Fungi: Use in Sustainable Agriculture and Land Restoration. Berlin Heidelberg: Springer-Verlag.

Weber, OB., (2014). Biofertilizers with Arbuscular Mycorrhizal Fungi inAgriculture. Di dalam Solaiman ZM, Abbott LK, Varma A. (editor). Mycorrhizal Fungi: Use in Sustainable Agriculture and Land Restoration. Berlin Heidelberg: Springer-Verlag. 